\title{
Review of energy saving and energy efficiency approaches applied in water sector in Russia
}

\author{
Nikolay Makisha* and Eleonora Shevchenko-Enns \\ Moscow State University of Civil Engineering, Yaroslavskoe shosse, 26, Moscow, 129337, Russia
}

\begin{abstract}
The article focuses on factors that might be crucial if an energy efficiency in the field of water supply and wastewater treatment is considered. There are most common drawbacks in maintenance of water supply and wastewater system described as well as the directions on the improvement of situation. The main directions of technological energy saving is the use of energy efficient technologies; energy efficient engineering solutions, and methods and equipment for regulating the operation of facilities and equipment.
\end{abstract}

\section{Introduction}

Requirements to quality of drinking water oblige to build treatment facilities, to carry out special water treatment. Nevertheless, these measures are sometimes not enough, as a sort of emergency might happen to pose a threat not only to nature but also to human life.

Wastewater treatment is necessary to reduce the amount of harmful impurities in the water. Reducing the level of wastewater pollution eventually reduces soil and air pollution. Wastewater treatment should be carried out with strict observance of all rules and sanitary norms that ensure the safety of man and his environment.

At present, energy saving is one of the priorities, which is associated with the shortage of basic energy resources, the increasing cost of their production, as well as global environmental problems. Energy saving is the implementation of production, scientific, technical, organizational, economic and legal measures aimed at achieving economically justified value of energy resources efficiency $[1,2]$.

\section{Energy saving approaches in water sector in Russia}

Energy saving in wastewater treatment is an urgent task at the present stage of development of engineering systems and structures. At present, most of the treatment plants have combined circuits. This is primarily due to the high requirements applied to the treatment of wastewater from petroleum products, as well as the complexity of the composition of incoming effluents. New aeration devices, physical methods of intensification of contact of

\footnotetext{
* Corresponding author: nmakisha@gmail.com
} 
gas and solid phases speak in favour of flotation method with its simplicity and efficiency that can become the main in the treatment of oily wastewater [3, 4].

Water supply, transportation and wastewater treatment are the processes with high energy consumption. In modern conditions, the cost of electricity, heat and fuel consumed by enterprises of water supply and sewerage is a significant part of the cost of production.

The total electrical power consumed by the city's domestic utilities counts nearly 4000 $\mathrm{kW}$ (in case of city with a capacity of approximately 100000 cubic meters per day of water) that includes operation of water treatment and supply of drinking water with average consumption of $2300 \mathrm{~kW}$, pumping of sewage $-600 \mathrm{~kW}$ and sewage treatment - from 700 to $1900 \mathrm{~kW}$. Here and further all specific calculations will be given to the above focused 'productivity, typical for the enterprises of the water sector of many Russian regional centers.

Unfortunately, the energy consumption of domestic utilities in Russia is significantly higher than in countries with similar climate. Therefore, reducing energy costs is now a priority. To this end, the Russian legislation has tightened the requirements for energy efficiency. In November 2009, the Federal law No. 261-FZ "Energy saving and energy efficiency" came into force, which outlined not only the priority areas of energy efficiency, but also the timing of the implementation of relevant measures.

Of course, when planning the introduction of energy-saving measures, the obvious truth is that energy saving is not the result and economic efficiency in general should be taking into account. When transferring foreign experience to Russian conditions, it is necessary to take into account that the EU has created much more favorable economic conditions for energy saving and alternative energy, up to the application of a two-fold increasing coefficient to the cost of "green" electricity. The absence of such incentive mechanisms in domestic practice can significantly worsen the economic indicators of energy saving declared by the results of foreign experience.

The most significant amount of electricity in the water sector is spent on supplying drinking water to consumers, pumping wastewater and wastewater treatment.

The main directions of reducing energy consumption for drinking water supply is the regulation of costs and pressures in the network, as well as reducing water losses.

The main sources of physical water losses are [5, 6]:

- hidden losses during transportation through the network $(90 \%$ of all leaks in the network);

- losses due to accidents and failures;

- unregistered connections to water networks;

- leaks through the seals of valves at water treatment stations, pumping stations;

- overflows from tanks;

- losses associated with the consumption of own needs, as well as natural water loss.

Water losses lead not only to loss of profit, but also to over-consumption of electricity spent on its production. In addition to leaks, there are two more factors that lead to inefficient use of electricity - additional pressure losses in the network due to the "air pockets" and the creation of excess pressure due to the lack of zoning and pressure regulation.

The main reason for this situation is the high level of wear of pipes and network infrastructure. Wear of communications has approximate value of $50-60 \%$ that in some cities exceeds $80 \%$. The unsatisfactory technical condition of the municipal infrastructure is the reason for the high level of water losses and a large number of man-made accidents. Unfortunately, in most cases, the rate of deterioration of networks significantly exceeds the rate of planned repair and replacement, resulting in the increasing number of failures in utility pipelines every year. One accident per year occurs on every third to fourth kilometer 
of the water supply network. Accident elimination costs are also a significant source of expenditures that can be reduced.

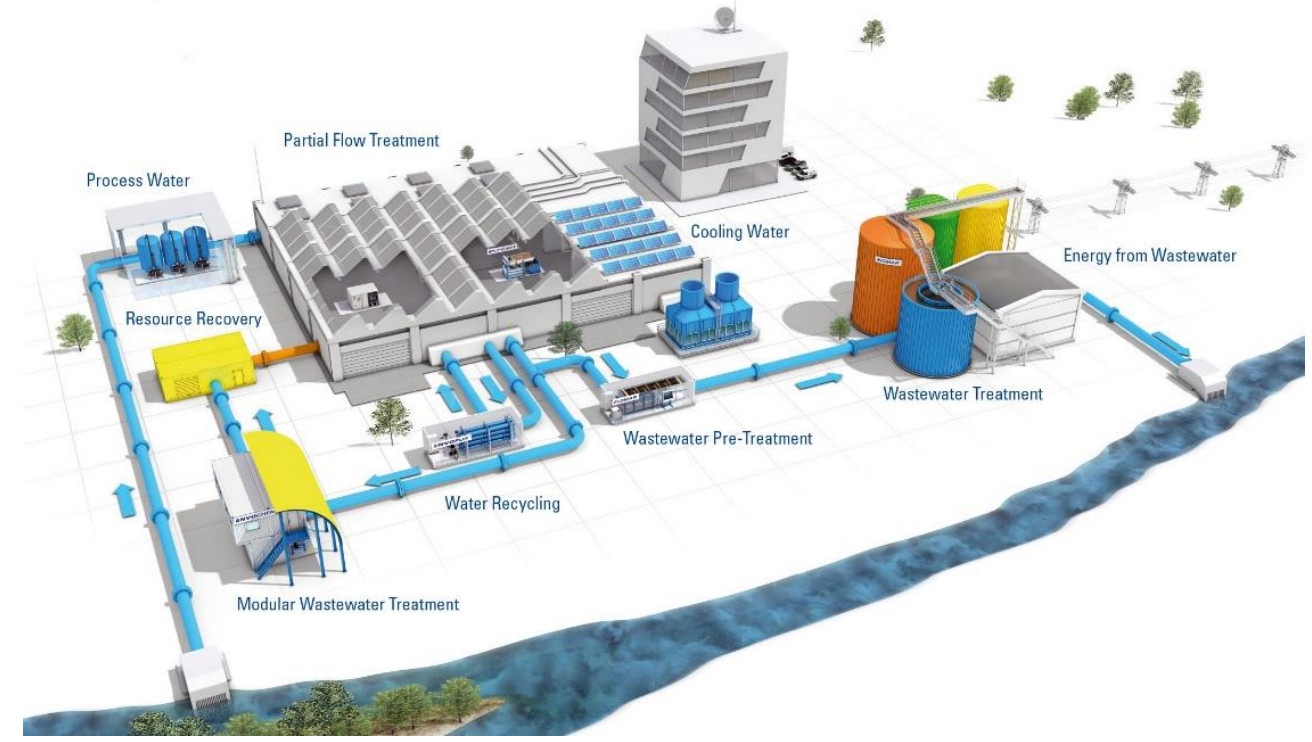

Fig. 1. Wastewater treatment with nearly zero emission

International water association has created a group of specialists working to solve the problem of reducing water losses, thereby increasing the energy efficiency of water supply and sanitation. This group has developed and successfully tested a method of reducing water losses.

The methodology includes work in four areas:

- pressure control in the network;

- leak detection and remediation;

- timely maintenance, repair and replacement of valves and pipelines;

- reduction of accidents and failures.

However, it is obvious that only a system approach throughout the water sector can reduce water losses to an economically acceptable level. At the same time, it is necessary to understand that financial investments in these areas are not only vital for the maintenance of water supply systems, but also are payback investments.

At present, it is clear that the further development and reliable operation of municipal systems is impossible without significant investment in their renewal. Taking into account the complexity and costs associated with the work in the city, it is important to choose reliable equipment with a long service life, with the shortest installation time, does not require regular maintenance.

The introduction of modern pipeline valves allows achieving certain results in terms of reducing water losses and improving the energy efficiency of the enterprise, provided the correct choice of the type of valves and guarantees its quality.

Traditional water treatment technologies consume relatively little energy, and their improvement in most cases leads to an increase in energy costs due to the transition to ozonation and membrane filtration technologies. The possibilities of energy generation in this area are very limited and largely reduced to the creation of mini-hydroelectric power stations in reservoirs of surface water sources, as well as local heating systems of industrial buildings using heat pumps.

Municipal treatment facilities provide significantly greater opportunities for energy saving in the technological process and energy generation. 
The most common in Russia conventional scheme of treatment facilities with primary settling tanks, aeration tanks and secondary settling tanks has extremely high energy consumption. Facilities with a capacity of 100000 cubic meters of wastewater per day containing $200 \mathrm{mg} / \mathrm{L}$ of suspended solids [TSS] and $180 \mathrm{mg} / \mathrm{L}$ of BOD $_{5}$ consume for daily needs nearly $700 \mathrm{~kW}$ of electric power. Implementation of intensive technological process, ensuring compliance with modern regulatory requirements, increases the average daily electrical power consumption to $1500-1900 \mathrm{~kW}$, including:

- deep oxidation of ammonium nitrogen (if its initial content is $30 \mathrm{mg} / \mathrm{L}$ ) requires 300 $500 \mathrm{~kW}$ of power more;

- UV disinfection of treated water needs additionally $150-200 \mathrm{~kW}$ of electric power;

- aerobic sludge stabilization - plus $300-400 \mathrm{~kW}$;

- mechanical sludge dewatering in centrifuges $-50-70 \mathrm{~kW}$ more.

\section{Energy conservation at wastewater treatment plants}

The main directions of technological energy saving is the use of:

- energy efficient technologies;

- energy efficient engineering solutions;

- techniques and equipment for regulating the operation of facilities and equipment.

Consider ways to implement the above areas of energy conservation. Table 1 presents the following energy-saving measures.

Table 1. Energy-saving measures

\begin{tabular}{|l|l|}
\hline \multicolumn{1}{|c|}{ Facility } & \multicolumn{1}{c|}{ Actions } \\
\hline Primary clarifiers & Use of primary clarifiers with zero presence of sediment on the bottom \\
\hline Aeration reactors & $\begin{array}{l}\text { Implementation of mixing zone in the beginning of treatment process and } \\
\text { provision of sewage recirculation towards it from the end part of reactor }\end{array}$ \\
\cline { 2 - 3 } & Use of aerobic stabilization of sludge \\
\cline { 2 - 2 } & Use of aeration systems providing fine bubbles \\
\cline { 2 - 3 } & $\begin{array}{l}\text { Even lay-out of aerators through-out the reactor to strabilize the distributed } \\
\text { oxygen amount and to rise to efficiency of the treatment process }\end{array}$ \\
\cline { 2 - 3 } & $\begin{array}{l}\text { Combination of aerators and mixers (mixing goes in non-aerated zones of the } \\
\text { reactors). Mixing can also be performed by means of hollow pipes or special } \\
\text { types of aerators. }\end{array}$ \\
\hline UV-desinfection & $\begin{array}{l}\text { Reduction of suspended solids concentration by means of preliminary filtration } \\
\text { of sewage after biological treatment stage }\end{array}$ \\
\hline Air blowers & $\begin{array}{l}\text { Permament control of air concentration to rise the efficiency of air dictribution } \\
\text { and to avoid excess or shortage of oxygen concentration in certain parts of } \\
\text { aeration reactor. }\end{array}$ \\
\hline
\end{tabular}

As the main amount of energy is spent on biochemical oxidation of wastewater pollution at treatment facilities, the amount of oxidized (organic) pollutions should be strictly limited. Primary sedimentation tanks are the most important technological tool for this limitation. If conventional treatment technology is applied, the aeration tanks should take sewer water with maximum possible degree of TSS removal. In the 1990s, the concentrations of pollutants of municipal wastewater coming to many Russian treatment facilities significantly decreased, which led to a decrease in the concentration of $\mathrm{BOD}_{5}$ in clarified water to 50-60 mg/L, however, this did not have a negative impact on the biological treatment processes. In the conditions of the existing facilities, improvement of the clarification efficiency can be achieved through the operation primary sedimentation tanks with a minimum (zero) level of sediment deposition on the bottom. 
When converting treatment facilities to deep oxidation of ammonium nitrogen, electricity costs for aeration can grow up to two times for the following main reasons:

- up to $45 \mathrm{mg}$ of oxygen is required directly for the oxidation process, e.g. $10 \mathrm{mg} / \mathrm{L}$ of ammonium nitrogen, which leads to the additional air supply (approximately 50\% more than in the conventional mode);

- stable nitrification requires higher concentrations of dissolved oxygen than simple oxidation of organic contaminants. This leads to a decrease in the solubility of oxygen in the sludge mixture by $10-15 \%$;

- achievement of residual concentrations of ammonium nitrogen of 0.4-1 mg/L requires significant processing time at a low rate of oxidation process, which, as a rule, reduces the efficiency of the use of oxygen of the air supplied to this zone of the aeration tank.

\section{Energy efficient engineering solutions}

This direction of reducing energy costs should be considered not only as the use of equipment with high efficiency, but in a broader sense: the use of equipment, which, due to its technical characteristics solves the problem with lower energy consumption [7].

The most significant contribution to the reduction of energy costs can make aeration systems. It is a well-known advantage of fine-bubble aerators: the smaller the gas bubble and the greater the path of the bubble to the surface, the higher the dissolution in the sludge liquor of oxygen. It should be noted that the presence of such a physical phenomenon as coalescence (sticking) of air bubbles limits the depth of expedient dispersion and generally significantly complicates the processes occurring in these systems [8].

The reverse side of the use of fine-bubble aerators is their clogging. This process is mostly typical to porous bulk dispersants (made of sintered mineral powder materials or fused plastic filaments), when they work beyond the optimal service life, or they are fed unfiltered dusty air. In such systems, the air pressure increases to the limits of the blower power (flow rate drops accordingly). If this is possible, the operation services are forced to connect an additional blower unit. When using traditional filter units, this leads to their tearing and a sharp decrease in the aeration efficiency. Modern aerators of this type are structurally more resistant to the negative consequences of pullouts (but not from problems with clogging).

Calculations show that the technical solution with the installation of energy-optimal number of aerators gives a payback in 1.5-2 years. However, sufficiently flexible air supply system in the aeration tanks is required to get the advantage of this gain. If there are only two operating blowers at the facilities, it is difficult to save anything on them $[9,10]$.

Another significant design factor is the use of an adequate layout scheme of aerators on the bottom of the aeration tanks, corresponding to the process need for oxygen. This is especially refers to the common in Russia and CIS countries aeration tanks with corridor scheme. Incorrect layout, in which there will be more aerators in some zones, while in other zones - less than required, will lead to the need to supply more air flow to the aeration tank than would be possible with the correct layout of the aerators. The efficiency of supplied oxygen is higher with a uniform layout of the aerators on the bottom.

A proven method of improving energy efficiency is the joint use of aeration systems and mixers. The formation of longitudinal flows in the aeration tank corridor increases the path of air bubbles to the surface and proportionally increases the solubility of oxygen. 


\section{Regulation of facilities and equipment}

The incoming flow of wastewater to biological treatment facilities tends to vary due to seasonal, weekly and daily cycles. The first two describe the circadian irregularity coefficient, the third - hour coefficient of irregularity $\left(\mathrm{K}_{\mathrm{gen} \text { max }}\right)$. However, it is less known that concentration of pollutants has its own irregularity depending to flow rate by time of day. This is because in the residential sector water consumption occurs simultaneously with domestic and fecal water pollution. In the night period, water consumption is mainly formed by leaks, which are not accompanied by pollution. Moreover, in recent decades, the volume of leaks has decreased significantly due to the switch to more reliable household sanitary appliances and mixers.

Thus, the mass load on the treatment facilities, which is a product of the volume load and pollution concentration, is subject to irregularity that is more significant.

The ratio of the average load on oxygen-consuming pollution $\left(\mathrm{BOD}_{\text {full }}+4,57 \mathrm{~N}-\mathrm{NH}_{4}\right)$ for 6 hours of the minimum load to the average for the day is 0,55 (which corresponds to $\mathrm{K}_{\text {gen.max }}$ value of 1,8 ). The $\mathrm{K}_{\mathrm{gen} \text { max }}$ value of the minimum load to the maximum (also for 6 hours) is about 0.45 . The last ratio shows the required minimum depth of air flow control. Given some unevenness and within the 6-hour range, the control depth should be up to $40 \%$ of the maximum feed.

At existing treatment facilities, in the absence of regulation of air supply, this phenomenon forms an extremely changeable picture of the quality of purified water. Thus, at the treatment facilities in Moscow, the measurement (on-line) of the concentration of ammonium nitrogen in the sludge liquor (as a criterion for the sufficiency of air supply to the facility) showed that it continuously varied in the range from 1 to $20 \mathrm{mg} / \mathrm{L}$. Such a high irregularity of the oxygen demand (in aeration reactors) creates a very large reserve for saving energy resources by providing the air tank with the amount of air that is necessary for the technological process. The need for air is usually determined by the concentration of dissolved oxygen measured by oxygen meters located at indicative points. Much less frequently (for simultaneous nitrification/denitrification) were used devices that directly measure the intensity of biochemical processes, but they are not widespread due to the high cost and complexity.

\section{Conclusions}

Based on the theoretical concepts of energy saving and energy efficiency in the field of sanitation, the following issues of energy saving can be identified:

- elimination of accidents failures resulting in reduction of water losses;

- implementation of modern pipeline valves;

- improvement of conventional technologies of water purification;

- use of energy efficient technologies and engineering solutions;

- implementation of special sensors and devices to control the operation of the facilities and equipment.

This work was financially supported by Ministry of Science and Higher Education of the Russian Federation (\#NSh-3492.2018.8).

\section{References}

1. D. Torregrossa, F. Hernández-Sancho, J. Hansen, A. Cornelissen, G. Schutz, J. of Cleaner Production, 167, 601-609 (2017) 
2. D. Torregrossa, U. Leopold, F. Hernández-Sancho, J. Hansen, J. of Environmental Management, 223, 1061-1067 (2018)

3. N. Makisha, T. Kazimirova, MATEC Web of Conferences, 144, 04013 (2018)

4. S. Di Fraia, N. Massarotti, L. Vanoli, Energy Conversion and Management, 163, 304313 (2018)

5. E. Galkina, O. Vasyutina, IOP Conference Series: Materials Science and Engineering, 365(2), 022047 (2018)

6. K. Smith, S. Liu, Y. Liu, S. Guo, Renewable and Sustainable Energy Reviews, 91, 4158 (2018)

7. R. Kollmann, G. Neugebauer, F. Kretschmer, B. Truger, M. Narodoslawsky, J. of Cleaner Production, 155, 119-129 (2017)

8. Q. Zhang, D. Sun, M. Wang, C. Yin, Energy Procedia, 142, 1230-1237 (2017)

9. I. Lee, H. Lim, B. Jung, M. F. Colosimo, H. Kim, Chemosphere, 140, 72-78 (2015)

10. J. Henriques, J. Catarino, J. of Cleaner Production, 142, 323-330 (2017) 